\title{
Percepções sobre os jogos de simulação de voo na formação de pilotos privados de avião
}

\author{
Lucas de Almeida, Universidade de São Paulo - USP, lucas2.almeida@usp.br \\ Cynthia Correa, Pós-Graduação em Estudos Culturais - USP, cynthia.correa@outlook.com
}

Resumo: Ao considerar o potencial dos jogos de simulação tanto para entreter como ensinar, o objetivo deste estudo é avaliar as percepções de estudantes do curso de Piloto Privado de Avião (PPA) sobre a prática de jogos de simulação de voo na formação do profissional. A pesquisa baseia-se em revisão de literatura, na aplicação de questionários online e presencial a alunos e em entrevistas com instrutores do curso de PPA do Aeroclube de São Paulo. Como principais resultados, os estudantes indicaram vantagens ao jogar em simuladores quanto ao entendimento sobre mecânicas e controles de voo, e funções básicas da aeronave. Limitações também foram observadas sobretudo relativas à falta de imersão, o que impossibilita simular efeitos fisicos e de feedback da aeronave no corpo do piloto.

Palavras-chave: Jogos de simulação, aprendizagem, formação profissional, aviação.

\section{Perceptions about flight simulation games in the training of airplane private pilots.}

Abstract: Given the potential of flight simulation games for both entertaining and teaching, the goal of this study is to evaluate the perceptions of students of the Airplane Private Pilot (APP) course on the practice of flight simulation games in the vocational training. The research is based on a literature review, the application of online and faceto-face questionnaires to students, and the conduction of interviews with instructors of the APP course of the Aeroclube de São Paulo. As primary results, students indicated advantages when playing simulators regarding an understanding of the mechanics and flight controls, and essential functions of the aircraft. Limitations were also observed, mainly about the lack of immersion that makes it impossible to simulate physical effects and feedback of the plane in the pilot's body.

Keywords: Simulation games, learning, professional training, aviation.

\section{Introdução}

Com o avanço tecnológico na projeção de ambientes digitais interativos, o interesse pelos jogos eletrônicos foi ampliado para diferentes nichos de mercado, transformando-se em uma indústria altamente lucrativa. Nesse panorama, o mercado global de jogos de simulação expande-se de forma constante, com uma previsão da taxa de crescimento anual de 17,4\% no período 2017-2021 (TECHNAVIO, 2017).

O propósito dos jogos de simulação é simular aspectos do mundo virtual apoiados em movimentos e situações do mundo real, a partir de plataformas de software e hardware. Nos simuladores, o design de jogo combina o caráter lúdico, que instiga a curiosidade e a vontade de jogar por diversão, a um conjunto de regras que torna $o$ ambiente simulado muito próximo à realidade, figurando como ferramentas essenciais para o treinamento e a capacitação em distintas áreas do saber, como a aviação. Séries de simulação de voo, como o Microsoft Flight Simulator X e o X-Plane, conquistaram espaço no mercado por tentarem reproduzir ao máximo as mecânicas de uma aeronave, limitadas apenas pelo nível de desenvolvimento da tecnologia à época. 
Ao analisar que esse modo de entretenimento digital representa o primeiro contato de muitos interessados em seguir a carreira de piloto, torna-se relevante investigar como os jogos de simulação de voo podem auxiliar na fase inicial de preparação à carreira. $\mathrm{O}$ objetivo geral da pesquisa é avaliar as percepções de estudantes do curso de Piloto Privado de Avião (PPA) sobre a prática de jogos de simulação de voo na formação do profissional. São objetivos específicos: conhecer o perfil do público, mapear os jogos de simuladores de voos preferidos, analisar o jogo de simulação de voo como ferramenta de entretenimento e/ou aprendizado, e identificar aspectos divergentes de experiências entre os ambientes real e virtual durante a formação do piloto.

Trata-se de um estudo de caráter qualitativo realizado com base em revisão de literatura e na aplicação de questionários e condução de entrevistas de tipo semiestruturada, de 10 de setembro a 10 de outubro de 2016. Participaram da pesquisa alunos e instrutores do curso de PPA no Aeroclube de São Paulo, por ser a maior escola de aviação do estado, e membros de três comunidades do Facebook populares entre pilotos brasileiros de diversos níveis de formação.

\section{Simuladores e o processo ensino-aprendizagem}

Desde o surgimento dos jogos eletrônicos, a ideia de simular ambientes reais no mundo virtual tem atraído distintos campos do conhecimento, porém, a maioria dos jogos de simulação é criada com intenções educacionais e de aprendizagem (Leemkuil; Jong; Ootes, 2000; Galvão; Martins; Gomes, 2000; Holzinger et al., 2009). A área militar é uma das pioneiras na utilização de videogames para o treinamento de soldados. Na década de 1950, a produção de simuladores computacionais com fins militares era feita "[...] com gigantes e lentos computadores programados em linguagem Fortran IV, rodando softwares puramente textuais" (Baladez, 2009, p. 1).

Para o autor, a evolução da simulação está vinculada à história militar, como ocorreu na Primeira Guerra Mundial, quando simuladores mecânicos foram criados para o treinamento de pilotos, para que tivessem mais segurança e alguma experiência ao pilotar aviões reais. Nota-se que os simuladores sempre tiveram um papel importante antes de serem projetados via computadores. Além dos simuladores mecânicos citados, simuladores analógicos de veículos foram usados na capacitação, permitindo a reprodução do controle de veículos com custos reduzidos e sem riscos à vida.

Para ser chamado de simulador, um sistema (software e hardware) deve atender aos requisitos máximos de precisão no virtual em relação à contraparte real. Contudo, quando se trata de jogos de simulação, os requisitos apresentam menos exigências de precisão visando o equilíbrio com uma jogabilidade prazerosa - as ações, estratégias e motivações dos jogadores (Aarseth, 2003), preservando o componente de ludicidade. Conforme Galvão, Martins e Gomes (2000), o conceito de simulação de jogo engloba uma mistura de características comuns de um jogo (competição, cooperação, participantes e regras) com elementos de simulação (incorporação de atributos críticos da realidade).

Com o aperfeiçoamento dos simuladores, a categoria simulação de voo teve ampla aceitação pelo público, com intuitos profissionais ou não. Os simuladores de voo são usados para finalidades distintas, por exemplo, formação de pilotos, concepção e desenvolvimento de aeronaves. $\mathrm{Na}$ atualidade, eles contam com as aplicações de realidade virtual, que foram incrementadas para superar os custos elevados de produção (Aslandere et al., 2014). A realidade virtual é descrita como um ambiente real ou simulado no qual o perceptor experimenta a tele presença, a percepção mediada de um ambiente (Steuer, 1992). Destacaram-se, inicialmente, a série Microsoft Flight Simulator 
(1982) e os jogos Falcon (1984) e Comanche (1992). Jogos de simulação de voo são formas compreensíveis de simular a aviação civil, retratando o cenário das aeronaves civis atuais e antigas, ambientadas em um panorama contemporâneo e em situações reais. Assim, os jogos explorados neste estudo (Microsoft Flight Simulator, X-Plane, FlightGear e Prepar3D) são clássicos de simulação de voo, diferentemente dos jogos $I L$ 2 Sturmovik e War Thunder, focados em combates aéreos fictícios e baseados em fatos sobre a Segunda Guerra Mundial.

Segundo Eler e Tavares (2015), o progresso dos simuladores se concentrou no realismo operacional e visual das aeronaves e do ambiente externo, sendo elaborados dispositivos capazes de simular cabines completas. Todavia, a função pedagógica do ensino da pilotagem de aeronaves não avançou. Logo, as etapas de prática em simulador dos cursos de formação de pilotos profissionais devem ser acompanhadas de modo direto e individual por tutores, aumentando o volume de trabalho e reduzindo a chance de implementar estratégias pedagógicas que impactem todo o grupo simultaneamente.

Independente das dificuldades, pesquisas indicam que os simuladores, com níveis de interatividade, jogabilidade e realismo cada vez mais expressivos e com maior potencial de imersão no ambiente virtual, podem contribuir em processos educacionais (Leemkuil; Jong; Ootes, 2000; Alves, 2008; Holzinger et al., 2009). Nesse sentido, buscase avaliar as percepções de estudantes do curso de PPA sobre a prática de jogos de simuladores de voo na preparação para a carreira. A seguir, perspectivas referentes à formação de pilotos privados no país serão apresentadas.

\section{Formação de um piloto de avião}

A formação de pilotos no Brasil ocorre por meio de cursos com conteúdo teórico e prático. Neste estudo, a atenção está centrada no curso de PPA, cuja habilitação constitui o primeiro nível da carreira de piloto de avião, sendo comentadas brevemente as demais etapas da formação de um piloto profissional. Conforme o Regulamento Brasileiro da Aviação Civil - RBAC n ${ }^{0} 61$ (ANAC, 2012), as carteiras de pilotos se dividem em: PPA para voos em aviões particulares de forma não remunerada, Piloto Comercial (PC) para atividades remuneradas, como táxi aéreo, e Piloto de Linha Aérea (PLA). É necessário completar o curso de PPA para realizar o de PC, e finalizá-lo para cursar o de PLA. Existem outros tipos de carteiras, como a de instrutor de voo (INVA) para atuar em aeroclube com a formação de PC, e carteiras de Piloto de Recreio (CPR) e Piloto Desportivo (CPD) para voos em aeronaves ultraleves.

Para a matrícula em qualquer curso, o interessado deve realizar um exame de saúde pericial com o objetivo de assegurar a aptidão física e mental de tripulantes e, em caso de aprovação, recebe o Certificado Médico Aeronáutico (CMA), que pode ser de $1^{\mathrm{a}}$ classe (para PPA, PC e PLA), de $2^{\mathrm{a}}$ classe (PPA) e de $4^{\mathrm{a}}$ classe (CPR e CPD). Para a conclusão dos cursos, é preciso realizar o curso teórico, ser aprovado no exame teórico da Agência Nacional de Aviação Civil (ANAC), cumprir as horas de voo previstas, e ser aprovado no voo de check. Para todos os cursos também é exigida uma idade mínima de 18 anos e ter completado o Ensino Médio (ANAC, 2012).

Segundo o Manual do Curso Piloto Privado Avião, o currículo é dividido em parte teórica e parte prática. A teoria é composta por três áreas: básica (introdução sobre a aviação civil e o funcionamento do sistema de segurança de voo), técnica (informações sobre a atividade de voo, meteorologia, regulamentos de tráfego aéreo e navegação aérea), e complementar (proteção e preservação da saúde do piloto), somando 270 horasaula. Quanto à prática, a grade reúne conhecimentos técnicos da aeronave e instrução no solo, seguidos pela prática de voo, com 40 horas de voo na aeronave selecionada para a 
instrução. Nessas 40 horas-aula, são abordadas manobras básicas e avançadas, simulações de panes e situações adversas, arremetidas no solo e no ar, cheques, inspeções e outros procedimentos visando preparar o aluno para situações reais (Brasil, 2004).

Nesse curso, não são usados simuladores homologados para abater horas de voo. Ressalta-se que há diferenças entre os simuladores homologados por órgãos aeronáuticos e os jogos de simulação. Para a US Federal Aviation Administration - FAA (2017), um simulador de voo deve recriar o ambiente de voo para propósitos de treinamento, capaz de replicar os parâmetros de resposta dos controles de voo para se observar e avaliar dados de interface e desempenhos de piloto, controlador e aeronave. A FAA reconhece e utiliza o Flight Simulator X e o X-Plane, e a ANAC apenas o X-Plane, como softwares de base para simulação, por cumprirem a função de reproduzir a imagem e a física necessárias.

O diferencial fica por conta da estrutura para além da tela, a presença de cabine, painel de instrumentos, controles da aeronave, sistema para reprodução de movimento (motion), todos fundamentais para a ambientação ao simular sensações visuais e físicas para o piloto, contribuindo para criar o aspecto de realidade, algo que o sistema sozinho não seria capaz de atingir.

\section{Materiais e métodos}

Para o desenvolvimento deste estudo de caráter qualitativo, foi realizada uma revisão de literatura com ênfase em temas-chave, como jogos eletrônicos, jogos de simulação e a relação com o processo de ensino-aprendizagem, bem como consultas a regulamentações sobre a carreira de piloto no Brasil. Por sua vez, o trabalho empírico consistiu na condução de entrevistas de tipo semiestruturada, que se fundamenta em questionamentos centrais abalizados em teorias e hipóteses sobre o assunto investigado, cujas informações coletadas contribuem para a descrição do fenômeno social em foco (Triviños, 1987).

Para a coleta de dados, foram elaborados dois instrumentos: um questionário com onze perguntas (duas abertas e nove fechadas) destinado aos alunos, e um roteiro de entrevista com sete questões abertas voltado aos instrutores de voo. As entrevistas ocorreram presencialmente no Aeroclube de São Paulo, a principal escola de aviação do estado e com o maior número de pilotos privados de avião em treinamento. Já via internet, membros das três comunidades do Facebook mais populares entre pilotos de diversos níveis de formação foram convidados por meio de post explicativo sobre a pesquisa: "Canal Piloto", "Aviação, Inovação \& Gestão" e "Piloto Privado e Comercial". As pesquisas pela internet têm a capacidade de atingir populações específicas com maior rapidez e menos custos, sendo ainda conveniente para o respondente devido a fatores como tempo e espaço (Malhotra, 2006).

No período de 10 de setembro a 10 de outubro de 2016, participaram 51 estudantes (33 online e 18 presenciais) e quatro instrutores de voo do Aeroclube de São Paulo, que não serão identificados para preservar o anonimato dos participantes. Três dos 51 questionários foram rejeitados: um por conter respostas incoerentes com a proposta, e outros dois por não preencherem o requisito de ter mantido contato prévio com jogos de simulação ligados à aviação. Portanto, 48 questionários validados, que correspondem ao valor de $100 \%$ para fins de análise desta pesquisa.

\section{Resultados e discussão}

Neste estudo, foram considerados exclusivamente alunos do curso de PPA, por ser o curso básico para todos que pretendem trabalhar remuneradamente na área, 
representando o primeiro contato oficial com o mundo da aviação. Quanto às entrevistas com os alunos do curso de PPA para avaliar as percepções sobre a prática de jogos de simulação de voo na formação teórica e prática do profissional, em um momento inicial foi examinado o perfil do público.

Todos os participantes (100\%) eram do sexo masculino e a maioria jovens entre 18 e 25 anos (64\%), seguidos por alunos de 26 a 30 anos (18\%), 31 a $45(10 \%), 45$ a 50 $(6 \%)$ e apenas um aluno acima de 50 anos $(2 \%)$. Esses dados condizem com a natureza do curso, afinal, por se tratar do passo inaugural visando à carreira de piloto, a procura elevada por parte dos jovens se destaca, por sua vez, quanto mais avançada a idade, menor o número de pessoas inscritas.

No que se refere aos jogos de simuladores de voos preferidos pelos estudantes conforme a faixa etária, os resultados são exibidos no Gráfico 1. Vale enfatizar que as respostas não eram excludentes, logo, o indivíduo poderia indicar mais de um jogo como resposta.

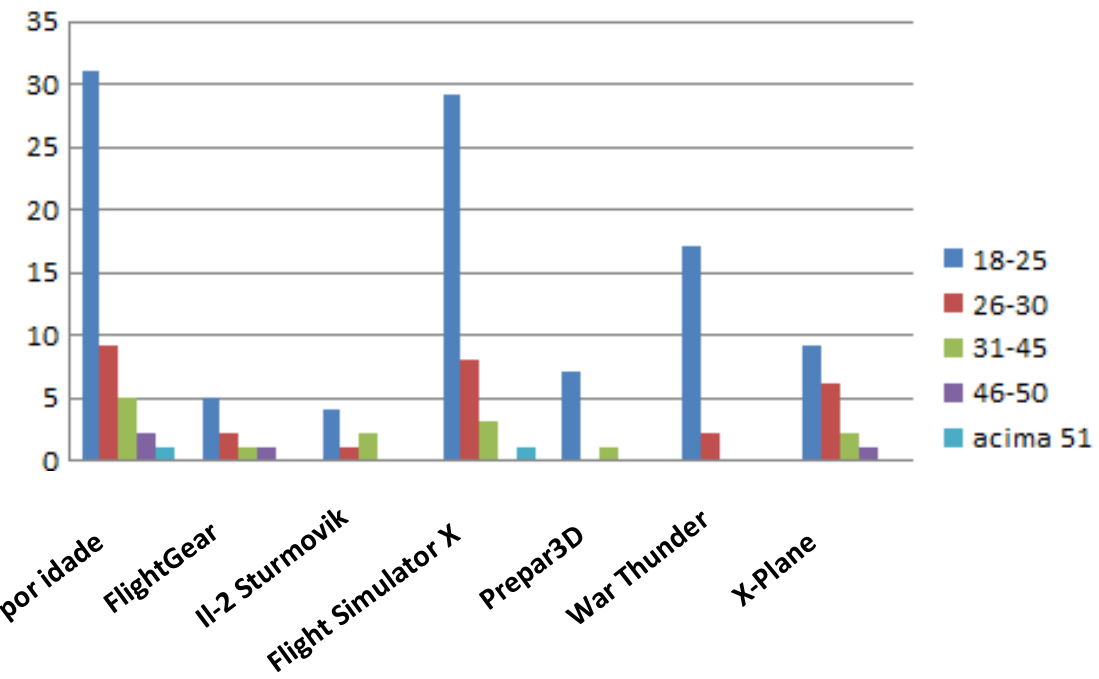

Gráfico 1. Relação de jogos preferidos por faixa etária.

Fonte: Elaboração própria.

Entre os jogos favoritos, o Microsoft Flight Simulator X lidera, citado por 85,4\% respondentes, consolidando-se como o mais popular em praticamente todas as faixas etárias. Em segunda posição, aparece a indicação do War Thunder predominantemente pelo público mais jovem, sendo $54,8 \%$ dos alunos com idades entre 18 e 25 anos, e $22,2 \%$ dos alunos entre 26 e 30 anos.

Já o $X$-Plane apresenta uma proporção similar a do Flight Simulator $X$ relativa à preferência por idade, entretanto, em uma escala menor. Na sequência, o jogo FlightGear também acompanha a proporção de idade com a maioria de adeptos na faixa etária entre 18 e 25 anos, contudo, em escala bem menor quando comparada ao X-Plane.

Ao analisar a escolha dos jogos a partir da faixa etária, deve-se analisar fatores como a tradição no mercado, popularidade, público-alvo, qualidade das imagens, entre vários outros. Jogos como o Microsoft Flight Simulator $X$ e o X-Plane são tradicionalmente reconhecidos por pilotos profissionais, aspirantes e usuários de jogos virtuais, enquanto jogos como o Prepar $3 D$ figuram como novidades no mercado.

Por sua vez, jogos como o War Thunder e IL-2 Sturmovik baseiam-se na competitividade entre jogadores e em uma dose de ficção ao simular combates da Segunda Guerra Mundial dinâmicos o suficiente para tornar o jogo atraente, mas ainda assim respeitando os limites físicos vigentes nos controles de tais aeronaves. Eles criam 
um ambiente competitivo, dinâmico e com uma carga lúdica maior que acaba por atrair principalmente a atenção dos mais jovens, pilotos profissionais ou não.

Para uma análise mais completa sobre o comportamento relativo aos jogos de simulação de voo, foram observados estudantes do curso de PPA que estavam na fase de aulas práticas, quando se voa em aeronave eleita pelo próprio candidato e sob a supervisão de um instrutor. Assim, referente à carga horária prática cursada (Gráfico 2), as duas faixas etárias líderes eram compostas por alunos prestes a concluir a quantidade necessária de horas (40\%), e alunos iniciantes da parte prática (33\%). Outros $27 \%$ da amostra estavam nas etapas intermediárias, sendo contemplados estudantes em distintos níveis de familiaridade e de experiência com aeronaves e com as técnicas de pilotagem.

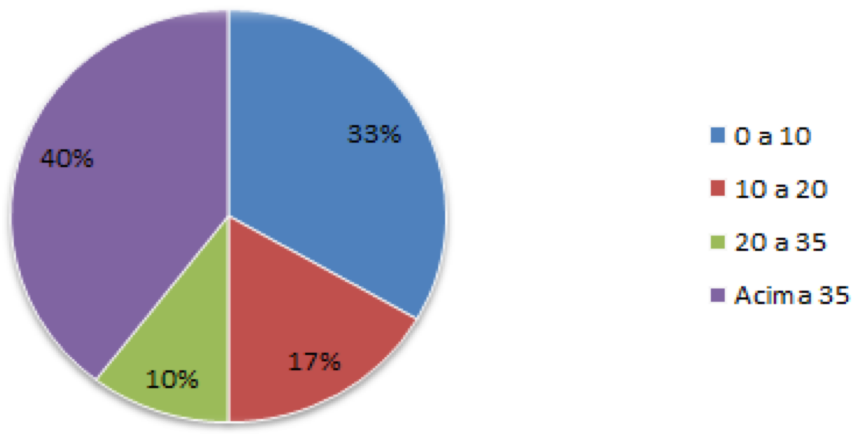

Gráfico 2. Quantidade de horas-aula acumuladas. Fonte: Elaboração própria.

Quando perguntados se tinham o hábito de jogar antes de ingressarem no curso de PPA, a absoluta maioria (81,3\%) afirmou ter interagido com algum jogo de simulação de voo antes de entrar efetivamente no campo profissional da aviação. De acordo com os instrutores, esse interesse inicial pelo simulador de voo é algo que acompanha a tomada de decisão pela carreira. Ao ser indagado sobre a proporção de alunos que tiveram contato prévio com jogos de simulação, o instrutor 04 comenta: "É difícil alguém não ter na verdade nenhum contato, é meio que até um caminho natural". O instrutor 03 confirma o relato: "É difícil dar números exatos, mas tem um monte de adolescente que vem aí que já tem contato. Pelo menos uma vez grande parte já teve".

Ao se avaliar os jogos de simuladores como uma forma acessível de explorar novos ambientes com o devido realismo, é natural que indivíduos interessados no assunto recorram a estes recursos. Simuladores de voo apresentam um custo baixo comparado ao valor da experiência real, aliado ao fato de não requererem nenhum conhecimento prévio ou exigência de uma idade mínima, mostrando-se especialmente atraentes para os jovens. Ademais, em geral, os jovens estão acostumados com o ambiente virtual e os processos de experimentação para decifrar as regras do ambiente.

Quanto à capacidade dos jogos em interferirem na escolha pelo curso de piloto, incentivando o interesse pela carreira, houve equilíbrio entre as posições. Um pouco mais da metade dos que jogavam antes de realizar o curso respondeu afirmativamente à questão $(51,3 \%)$, relatando que os jogos influenciaram de certo modo na tomada de decisão. Para esse grupo de estudantes, prevalece um consenso de que bases de entendimento sobre pilotagem podem ser criadas ao simular um ambiente, rotinas, tarefas e responsabilidades ligadas ao que muitos aspiram como profissão. Consequentemente, o jogador passa a analisar os pontos positivos e negativos, confirmar expectativas pré-concebidas ou se frustrar com outras, proporcionando uma melhor compreensão e ajudando no processo decisório sobre a carreira.

Sobre a visão relativa aos jogos, uma parcela majoritária dos participantes (83\%) 
entende que os jogos de simulação apresentam tanto a habilidade de entreter quanto de treinar, auxiliando no aprendizado de maneira proveitosa e divertida para a formação do piloto. O aluno 05 relata que "[...] para mim, pelo menos, eu procuro algo legal para jogar, mas eu procuro fazer algo mais real, para eu poder aplicar de uma forma mais benéfica, saber como um modelo se comporta, treinar fonia etc.". Já $15 \%$ consideram os jogos como atividade de lazer e entretenimento, enquanto outros $2 \%$ os avaliam como material educativo complementar ao curso.

Ao questionar os instrutores sobre o papel do simulador como ferramenta de aprendizagem complementar ao curso, verifica-se uma confirmação sobre as perspectivas dos alunos, entretanto com ressalvas. Todos os instrutores relataram que os simuladores são úteis no que se refere a conhecer noções essenciais e comandos básicos da aeronave. Todavia, ao longo do curso prático, para os procedimentos abordados, eles gradualmente perdem a utilidade devido à falta de imersão e sensação necessárias para o entendimento prático das manobras e atitude de voo.

Quando perguntados sobre os pontos positivos dos jogos de simulação, as respostas foram unânimes, $100 \%$ dos instrutores contaram que tiveram um retorno positivo na experiência real de pilotagem no caso de alunos iniciantes. Entre os itens mais valorizados, destacam-se a ambientação, o fato dos jogos expressarem por meio de imagem o ambiente real de uma aeronave, a posição dos painéis, dos controles, o campo de visão realístico durante as fases do voo, proporcionando certa familiarização. Assim, os alunos tendem a classificar a experiência em simuladores de voo como benéfica, ao transmitir informações sobre o funcionamento dos instrumentos dos painéis e a utilidade de vários sistemas, seja complementando uma abordagem teórica prévia ou através de sondagem.

Outro elemento lembrado pelos estudantes foi a chance de simular virtualmente os comandos primários de um avião e a física aplicada sobre ele. Tal entendimento é de extrema utilidade para introduzir indivíduos que nunca tiveram contato com a movimentação de uma aeronave, além de permitir aos usuários familiarizados com essa noção que treinem e explorem a movimentação em um ambiente seguro. Por meio de tentativas e erros, o aluno pode se aprofundar nas dinâmicas não apenas da aeronave eleita para a pilotagem, como também de diversos modelos, tamanhos e características para ampliar o conhecimento, reforçando a relação entre os simuladores e o campo de ensino e aprendizagem (Leemkuil; Jong; Ootes, 2000; Alves, 2008; Holzinger et al., 2009).

Ademais, o reforço à parte teórica mostra-se predominante, sendo citado como algo recorrente. Nota-se que durante a primeira etapa do curso de PPA não existe parte prática, criando uma expectativa de voar que só é intensificada, podendo levar o estudante a recorrer aos jogos de simulação. Desse modo, uma pequena parcela de ansiedade pode ser suprida, além disso, o aluno pode analisar e praticar conceitos aprendidos de uma forma consciente, uma vez que o conjunto de regras que torna o simulador realista procura imitar rigorosamente elementos da contraparte real (Galvão; Martins; Gomes, 2000). Ao se estudar essas regras no curso teórico, é natural a transposição para o ambiente do jogo, tornando viável explorar a informação a fim de facilitar o aprendizado, como declara o aluno 04: "Nos jogos, sempre procurei manter o mais próximo da realidade possível. Desde o preenchimento do plano de voo, ao cálculo de combustível, check list, fonia e afins. Além, é claro, de treinar no jogo o que aprendi no aeroclube".

Ao analisar a oportunidade de jogar de forma cooperativa, principalmente nos jogos destinados à aviação civil, surge uma vantagem de desenvolver um conhecimento na área de comunicação narrada por muitos estudantes e reafirmada por instrutores. A capacidade de unir jogadores em funções diferentes e estabelecer comunicação entre eles via áudio permite simular rotinas de operação. Ainda, a estrutura de comunicação via 
rádio semelhante a real possibilita que o aluno exercite essa prática, como sugere o instrutor 01: "Quando você usa sério para realmente fazer voo virtual, você acaba entrando com a parte de fonia e até desenvolvendo uma dicção que os alunos que até então não tiveram contato demoram um pouco para desenvolver".

No que diz respeito à identificação de aspectos divergentes de experiências entre os ambientes real e virtual durante o processo de formação do piloto privado, os estudantes informam que não há necessariamente desvantagens no uso do simulador (52\%), mas algumas diferenças são notáveis. A principal reclamação se refere às reações psicofísicas ao voar de verdade. Por outro lado, a incapacidade de simular as forças da física como a força $G$ e efeitos atmosféricos no corpo também é mencionada com frequência devido à limitação natural do jogo.

O controle da aeronave, segundo os entrevistados, representa um grande diferencial, ao se avaliar tempo de resposta dos comandos, sensibilidade e precisão dos controles, bem como a reação referente ao vento. Nas palavras do aluno 01: "O maior erro que eu cometi em relação aos games foi sobre o pouso devido à dificuldade na vida real, pois é necessário levar em consideração a velocidade e o vento, o que não é necessário nesses games". Enquanto o aluno 02 revela: "Voava no Flight Simulator X já fazia um tempo, e quando iniciei minhas aulas práticas de PPA tive muitas dificuldades de controle e reação na aeronave. Por muitas vezes, saí frustrado da aula por não conseguir dominar um procedimento e manobra. Mas tudo é prática e com o tempo você se adapta”.

A falta de correspondência com o ambiente real não ocorre apenas pela limitação física dentro do simulador, mas pela ausência de imersão e meios capazes de fazer o piloto sentir fisicamente as sensações que um piloto sentiria no momento do voo. O estol - termo utilizado na aviação e aerodinâmica para indicar uma perda total de sustentação na aeronave - no curso prático é observado, treinado e prevenido justamente por meio de sensações físicas proporcionadas pela aeronave. Como ilustrado no depoimento do instrutor 02: "é muito feeling... o estol, por exemplo, você sabe porque você sente que a aeronave vai começar a vibrar, coisa que não é possível identificar no Flight Simulator".

Um dos pontos que merece atenção é a falsa ilusão de já saber dominar uma aeronave que os simuladores podem passar para alguém que ainda não teve contato com a experiência autêntica de voar. Alguns estudantes veteranos em simuladores podem apresentar certa resistência a aprender conceitos durante o curso, por estarem acostumados com os simuladores. O problema é que procedimentos mudam de aeronave para aeronave, e rotinas e medidas de segurança nem sempre são ensinadas nos jogos, assim como regulamentos vigentes não costumam ser explorados, contudo, constituem um componente importante do conhecimento e devem ser seguidos na pilotagem.

Sobre esse aspecto, algumas pessoas são radicais, como o aluno 03, ao expor que: "Não tem nem comparação, um ao outro (real para o virtual), é super diferente. Mas percebi que tinha muitos erros, e o que eu achava que era certo, era o contrário, e por aí vai...". Conforme o instrutor 01 , às vezes, eles acham que conhecem tudo, e que o voo de verdade é igual ao Flight Simulator: "O legal é pegar aquele aluno que está começando no Flight Simulator, acha que é legal e vem para cá, não aquele cara que já tem 5 mil horas no jogo, porque tem vezes que você tenta colocar alguma coisa na cabeça dele do tipo olha você tem que pousar dessa forma. E eles [dizem] 'mas é que no Flight Simulator... o nariz vem sempre em cima e eu tenho que pousar que nem boeing aqui', e não é assim, é difícil convencer o cara a fazer as coisas certas". Logo, é evidente o conflito entre estudantes que jogam em simuladores e instrutores na hora de voar em aeronaves, quando procedimentos de segurança e regulamentos precisam ser obedecidos totalmente.

Concernente aos jogos sérios, apesar de a maioria dos jogos analisada tender ao entretenimento, o $X$-Plane e o Prepar $3 D$ apresentam um viés destinado ao treinamento e 
ao uso profissional. O X-Plane oferece a opção de upgrade para uma versão aprovada pela FAA com o intuito de focar no treinamento do usuário, além de uma optimização nos painéis de controle para funcionar ao lado do hardware necessário certificado para tal (cockpit e controles de voo), transformando-o em um simulador homologado. Já o Prepar $3 D$ apresenta licenças que variam de uso para aprendizado, treino e instrução até versões profissionais com plataformas de treinos para aeronaves civis e militares, operações de controle de tráfego, veículos de solo e resposta a desastres desenvolvidos pela Lockheed Martin. É importante ressaltar que enquanto jogos como o X-Plane, Prepar3D e o Microsoft Flight Simulator $X$ podem ser usados em conjunto com o hardware necessário para criar um simulador homologado, empresas como a Elite Simulation Solutions optam por desenvolver os próprios software e hardware focando na construção e comercialização de simuladores que já atendam as normas.

\section{Conclusões}

A partir das análises, constata-se que os simuladores de voo realizam um bom desempenho ao introduzir o mundo da aviação ao público em geral, funcionando ainda como ferramentas de aprendizagem para aspirantes à carreira em níveis que vão depender do comprometimento e visão de cada jogador. A simulação permite o aprofundamento em mecânicas, tais como a física e a dinâmica de voo, fonia, noção espacial e procedimentos básicos, com a possibilidade de treinar e aperfeiçoar essas mecânicas em segurança e com um custo bem menor quando comparado a aulas em aeronaves.

Além da capacidade instrutiva, os simuladores, que podem ser considerados formas de entretenimento digital, são capazes de despertar o interesse na área de maneira descontraída e também consolidar interesses prévios ajudando na tomada de decisão sobre cursos e carreiras no setor. Apesar do reconhecido valor para o ensino e a aprendizagem apontado por estudantes e instrutores do curso de PPA, observa-se que melhores resultados são obtidos por meio da junção de conhecimentos trabalhados na parte teórica com a possibilidade de exercê-los e testá-los em ambiente virtual. Uma vez que, para a parte prática, a física das aeronaves em relação aos ventos, forças exercidas no aluno e atitude de voo representam uma etapa essencial do treinamento, porém não podem ser simuladas em jogos.

Portanto, entre os aspectos negativos, uma parcela significativa refere-se à inabilidade do simulador de transmitir sensações físicas para o piloto, o que só seria possível com equipamentos mais avançados, como os simuladores homologados por órgãos oficiais. A dificuldade é que estes tipos de simuladores não são acessíveis e custam caro, diferentemente dos jogos de simulação examinados. Em síntese, as desvantagens apresentadas nos jogos de simulação são superadas pelos pontos positivos, conforme o propósito de oferecer uma experiência prazerosa, entretanto, realística. Assim, o simulador de voo pode servir como uma ferramenta eficaz para o aluno testar conhecimentos e explorar recursos com as restrições que um ambiente de jogo apresenta.

Como limitações da pesquisa, reconhece-se que as entrevistas presenciais foram conduzidas somente na cidade de São Paulo e com um grupo seleto de estudantes e instrutores. Todavia, a estratégia de trabalhar com grupos pelo Facebook foi uma forma de envolver estudantes de outras regiões. Além disso, faltaram táticas participativas para analisar o desempenho prático dos alunos, como pesquisas in loco, a fim de relatar com detalhes as experiências observadas. No que diz respeito a perspectivas em termos de estudos, propõe-se abordar amostras maiores de participantes, de diversas cidades e escolas, em outras etapas e cursos para avaliar as percepções relativas ao uso de simuladores na formação de pilotos. 


\section{Referências}

AARSETH, E. J. O jogo da investigação: abordagens metodológicas à análise de jogos. Caleidoscópio: Revista de Comunicação e Cultura, n. 4, p. 9-23, 2003.

AGÊNCIA NACIONAL DE AVIAÇÃO CIVIL. ANAC. Resolução n ${ }^{\circ}$ 237, de 5 de junho de 2012. Aprova o Regulamento Brasileiro da Aviação Civil no 61. Diário Oficial da União, Brasília, DF, 6 jun. 2012.

ALVES, L. Relações entre os jogos digitais e aprendizagem: delineando percurso. Educação, Formação \& Tecnologias, v. 1, n. 2, p. 3-10, 2008.

ASLANDERE, T.; DREYER, D.; PANKRATZ, F.; SCHUBOTZY, R. A generic virtual reality flight simulator. DLR Portal, 2014. Disponível em: $<$ http://elib.dlr.de/90891/1/main.pdf>. Acesso em: 13 mar. 2017.

BALADEZ, F. O passado, o presente e o futuro dos simuladores. Fasci-Tech, v.1, n. 1, p. 29-40, 2009.

BRASIL. Ministério da Defesa. Departamento de Aviação Civil. Portaria DAC n ${ }^{0}$ 954/DGAC, 27 de agosto de 2004. Aprova a terceira edição do Manual do Curso Piloto Privado Avião. Diário Oficial da União, Brasília, DF, 6 set. 2004.

ELER, E.; TAVARES, O. L. Uma arquitetura pedagógica para aprendizagem de pilotagem de aeronaves. In: CONGRESSO BRASILEIRO DE INFORMÁTICA NA EDUCAÇÃO, 4., 2015, Maceió. Anais... Maceió: UFAL, 2015. p. 644-653.

FEDERAL AVIATION ADMINISTRATION - FAA. Flight Technologies \& Procedures Division, 2017. Disponível em: $<$ https://www.faa.gov $>$. Acesso em: 13 mar. 2017.

GALVÃO, J. R; MARTINS, P. G.; GOMES, M. R. Modeling Reality with Simulation Games for a Cooperative Learning. In: WINTER SIMULATION CONFERENCE, 2000, Orlando. Proceedings... Orlando: Institute of Electrical and Electronics Engineers, 2000. p. $1692-1698$.

HOLZINGER, A.; KICKMEIER-RUST, M. D.; WASSERTHEURER, S.; HESSINGER, M. Learning performance with interactive simulations in medical education: Lessons learned from results of learning complex physiological models with the haemodynamics simulator. Computers \& Education, v. 52, n. 2, p. 292-301, 2009.

LEEMKUIL, H.; JONG, T.; OOTES, S. Review of educational use of games and simulations. Amsterdam: University of Twente, 2000.

MALHOTRA, N. Pesquisa de marketing: uma orientação aplicada. Porto Alegre: Bookman, 2006.

STEUER, J. Defining Virtual Reality: dimensions determining telepresence. Journal of Communication, v. 42, n. 4, p. 73-93, 1992. 
TECHNAVIO. Global Gaming Simulators Market 2017-2021 Report. Disponível em: $<$ https://www.technavio.com/report/global-consumer-electronics-global-gamingsimulators-market-2017-2021>. Acesso em: 7 abr. 2017.

TRIVIÑOS, A. N. S. Introdução à pesquisa em ciências sociais: a pesquisa qualitativa em educação. São Paulo: Atlas, 1987. 